\title{
Major histocompatibility complex (Mhc) class Ib gene duplications, organization and expression patterns in mouse strain C57BL/6 Masato Ohtsuka*1, Hidetoshi Inoko ${ }^{1}$, Jerzy K Kulski ${ }^{2}$ and Shinichi Yoshimura ${ }^{1}$
}

Address: ${ }^{1}$ Division of Basic Molecular Science and Molecular Medicine, School of Medicine, Tokai University, Bohseidai, Isehara, Kanagawa 2591193, Japan and ${ }^{2}$ Centre for Forensic Science, The University of Western Australia, Nedlands, WA, Australia

Email: Masato Ohtsuka* - masato@is.icc.u-tokai.ac.jp; Hidetoshi Inoko - hinoko@is.icc.u-tokai.ac.jp; Jerzy K Kulski - kulski@mac.com; Shinichi Yoshimura - syoshimu@is.icc.u-tokai.ac.jp

* Corresponding author

Published: 17 April 2008

BMC Genomics 2008, 9:178 doi:10.1186/147|-2164-9-178

This article is available from: http://www.biomedcentral.com/l47/-2/64/9/178

(c) 2008 Ohtsuka et al; licensee BioMed Central Ltd.

This is an Open Access article distributed under the terms of the Creative Commons Attribution License (http://creativecommons.org/licenses/by/2.0), which permits unrestricted use, distribution, and reproduction in any medium, provided the original work is properly cited.
Received: 7 November 2007

Accepted: 17 April 2008

\begin{abstract}
Background: The mouse has more than 30 Major histocompatibility complex (Mhc) class lb genes, most of which exist in the $\mathrm{H} 2$ region of chromosome 17 in distinct gene clusters. Although recent progress in Mhc research has revealed the unique roles of several Mhc class lb genes in the immune and non-immune systems, the functions of many class lb genes have still to be elucidated. To better understand the roles of class $\mathrm{lb}$ molecules, we have characterized their gene duplication, organization and expression patterns within the $\mathrm{H} 2$ region of the mouse strain $\mathrm{C} 57 \mathrm{BL} / 6$.
\end{abstract}

Results: The genomic organization of the $H 2-Q,-T$ and $-M$ regions was analyzed and $2 \mathrm{I}$ transcribed Mhc class lb genes were identified within these regions. Dot-plot and phylogenetic analyses implied that the genes were generated by monogenic and/or multigenic duplicated events. To investigate the adult tissue, embryonic and placental expressions of these genes, we performed RT-PCR gene expression profiling using gene-specific primers. Both tissue-wide and tissue-specific gene expression patterns were obtained that suggest that the variations in the gene expression may depend on the genomic location of the duplicated genes as well as locus specific mechanisms. The genes located in the H2-T region at the centromeric end of the cluster were expressed more widely than those at the telomeric end, which showed tissue-restricted expression in spite of nucleotide sequence similarities among gene paralogs.

Conclusion: Duplicated Mhc class lb genes located in the $H 2-Q,-T$ and $-M$ regions are differentially expressed in a variety of developing and adult tissues. Our findings form the basis for further functional validation studies of the Mhc class lb gene expression profiles in specific tissues, such as the brain. The duplicated gene expression results in combination with the genome analysis suggest the possibility of long-range regulation of $\mathrm{H} 2-\mathrm{T}$ gene expression and/or important, but as yet unidentified nucleotide changes in the promoter or enhancer regions of the genes. Since the Mhc genomic region has diversified among mouse strains, it should be a useful model region for comparative analyses of the relationships between duplicated gene organization, evolution and the regulation of expression patterns. 


\section{Background}

The Major Histocompatibility Complex (MHC) genomic region harbors duplicated genes that express protein molecules responsible for the rejection of transplanted tissue, restricted antigen presentation and the recognition of self and non-self $[1,2]$. The Mhc genomic region in the mouse, located on chromosome 17 , is named $\mathrm{H} 2$ and the genes within this region are usually classified into three distinct classes (I to III) based on their structure and function [3]. The class I molecules generally elicit immune responses by presenting peptide antigens derived from intracellular proteins to T lymphocytes and their genes can be classified into two groups, the classical Mhc class I (class Ia) genes and the non-classical Mhc class I (class Ib) genes. The classical Mhc class Ia genes, such as $H 2-K$ and $-D$ in the mouse, are highly polymorphic, expressed widely and present antigens to CD8+ cytotoxic T cells. To date, most studies of the MHC class I genomic region have been focused on the immunological function of class Ia molecules [4-6].

The non-classical class Ib molecules are structurally similar to the classical class Ia proteins, but in contrast to the classical class Ia proteins, they have limited or no polymorphisms. They are more restricted in their tissue expression and some have functions other than antigen presentation to CD8+ T cells. The non-classical class Ib proteins have shorter cytoplasmic tails and some of them lack consensus residues associated with peptide binding [7]. The mouse is considered to have more than $30 \mathrm{Mhc}$ class Ib genes in the genome [3]. Most Mhc class Ib genes are located at the telometric end of the $2 \mathrm{Mb}-\mathrm{H} 2$ region within the H2-Q, $-T$ and $-M$ sub-regions, which were originally mapped and defined by recombination analysis. Although the non-classical class Ib genes are involved in immunological functions like the classical class Ia genes, they generally serve a more specialized role in the immune responses. The expression and function of some non-classical class Ib genes, including H2-T23 (Qa-1), M3 and -T3 (TL antigen), have been analyzed in detail. For example, Qa-1 is involved in the suppression of CD4+ T cell responses via CD94/NKG2A or CD94/NKG2C receptors $[8,9]$. The peptide presentation by the Qa-1 molecule may also have a role in $\mathrm{CD} 8+$ regulatory $\mathrm{T}$ cell activity [10]. H2-M3 molecules prime the rapid response of CD8+ T cells by presenting $N$-formylated bacterial peptides [11]. The TL antigen is involved in the formation of memory CD8+ T cells [12] and in the regulation of iIEL responses in the intestine by interaction with homodimeric CD8 alpha receptors [13].

The class Ib molecules are also involved in non-immune functions. For example, the H2-M1 and -M10 families of the class Ib genes specifically interact with the V2R class of pheromone receptors presented on the cell surfaces of the vomeronasal organ $[14,15]$. The Qa-2 proteins encoded by H2-Q7 and -Q9 class Ib genes influence the rate of preimplantation embryonic development and subsequent embryonic survival [16]. In addition, the class I molecules have recently been shown to contribute to the development and plasticity of the brain $[17,18]$. So far, there is little information about which of the non-classical class Ib genes are involved in this function.

The molecular functions of many of the other class Ib molecules are still far from being understood and even the expression patterns for many of the Mhc class Ib genes remain to be elucidated. The Mhc class Ib genes are members of gene clusters that have been generated by different rounds of duplication and deletion [19]. In the mouse, the telomeric $1 \mathrm{Mb}$ of the Mhc including the $H 2-\mathrm{M}$ region was well characterized using the 129/Sv inbred strain [20]. The possible evolutionary fates of duplicated genes are nonfunctionalization, neofunctionalization or subfunctionalization [21]. Genes recently duplicated may even have the same functions by having and using identical or similar expression domain sequences. In order to better understand the role of class Ib molecules expressed by duplicated genes in different tissues, we have undertaken to examine, identify and characterize the Mhc class Ib gene duplication, organization and expression patterns within the $H 2$ region of the mouse strain $\mathrm{C} 57 \mathrm{BL} / 6$.

The whole genome of the laboratory mouse strain C57BL/ $6 \mathrm{~J}$ has been almost fully sequenced [22]. However, the genomic organization of the Mhc class I region of mice varies markedly between different haplotypes and inbred strains [20]. In the present study, we selected Mhc class Ib DNA sequences from the mouse genome database (NCBI Entrez Genome Project ID 9559), and characterized the organization of the Mhc class Ib genomic region for the mouse C57BL/6 strain (haplotype b). Expression patterns of each of the Mhc class Ib genes were examined by RTPCR using gene-specific primer sets, and we identified Mhc class Ib genes with either tissue-restricted expression or tissue-wide expression. We also identified monogenic and multigenic duplicated regions within the $H 2-T$ region of the mouse inbred-strain, $\mathrm{C} 57 \mathrm{BL} / 6$. Based on the results of our comprehensive analysis of the Mhc class Ib gene duplication, organization and expression patterns, we discuss the possible relationships and regulatory outcomes between the genomic location and expression patterns of the mouse Mhc class Ib duplicated genes.

\section{Results and Discussion Identification and genomic organization of transcribed Mhc class Ib genes}

As the aim of this study was to determine the tissue expression patterns for each of the duplicated Mhc class Ib genes, we first needed to identify the location and the number of transcribing Mhc class Ib genes in the mouse genomic 
sequence [22]. Although a nearly complete mouse genomic sequence of this region was available in the public database, there were many large sequence gaps and incomplete annotations for the sequence when we started this study. Therefore, we predicted the putative Mhc class Ib genes from the genomic contig NT_039650.2 by using the GENSCAN program. This analysis identified $19 \mathrm{Mhc}$ class Ib-like sequences with coding potential (data not shown). Based on these sequences and the information obtained from the public databases, we designed genespecific primer sets (Table 1 ) and confirmed the expression of the predicted genes by RT-PCR against a panel of cDNA tissues as described below. The nucleotide sequences, determined by direct-sequencing of the RTPCR-amplified fragments, were registered with the GenBank/DDBJ sequence database and given the accession numbers, [GenBank:AB266872, AB266873, AB267092- $\underline{A B 267096}$. As a result, a total of 15 expressed genes were identified and mapped onto the current genomic sequence ("GS" number in Figure 1). Although there may be a possibility of misassemblies or missequencing of genomic sequence, most of the assembled sequence, especially the order of genes, is thought to be correct considering the fact that the distributions of restriction sites (such as EcoRI, BamHI and KpnI) are consistent with previous reports (data not shown) [23,24], and that the cDNA sequences we examined were perfectly matched with genomic sequence. However, there was no genomic sequence corresponding to the H2-Q8 and -Q9 genes that are believed to be present in $\mathrm{C} 57 \mathrm{BL} / 10$ (haplotype b). At present, we do not know with certainty whether the assembly of the genome is completely correct in this region. Although the H2-Q5 locus was annotated as H2-Q8 in the genome database, we designated this locus as H2-Q5 for the following reasons. 1) This locus was consistent with the physical map position of H2-Q5 in the previous report [23], and 2) the DNA sequence of this locus is different from the H2-Q8 gene of C57BL/10 (U57392). This analysis in combination with a previous report [25] revealed that a total of at least $21 \mathrm{Mhc}$ class Ib genes, 7 in the H2-Q region, 11 in the H2-T region and 3 in the H2-M region are definitely transcribed in the C57BL/6 mouse. However, in the present study, we did not consider the H2-M1, -10 family of $M h c$ class Ib genes that are located outside the H2-Q and - $T$ genomic regions.

Table 2 presents the $\mathrm{H} 2$ gene numbering system for C57BL/6 mice (haplotype $\mathrm{b}$ ) that we have used in this paper. We designated each $\mathrm{H} 2$ gene with reference to the genomic locations and designations used by others $[23,24,26]$. The nucleotide sequences were determined for the full-length cDNAs expressed by the genes H2-T23, T22, -T15, -T5 and -M5 and submitted to the GenBank database [GenBank:AB359227-AB359231]. All genes exhibited a standard class I structure with an alpha 1, alpha 2, alpha 3 and transmembrane (TM) domain.

\section{Monogenic and multigenic duplications}

Mhc class I genes tend to diversify between species or strains as a result of local duplications and deletions [27]. As local duplication often generates similar genes with similar expression pattern and functional redundancy, it is important to understand the genomic organization and evolution of the Mhc class Ib regions. Hence, dot-plot analysis was conducted by comparing the sequences of the $H 2-\mathrm{Q}$ and $-T$ regions to themselves (Figure $1 \mathrm{~B}$; 240,000 bp for H2-Q cluster, 250,000 bp for H2-T cluster). In addition to the short diagonal lines seen in the dot-plots due to the similarity of each Mhc class I gene, long diagonal lines that indicate evidence of local duplications are seen in both the H2- $Q$ and - $T$ regions. Regarding the H2-Q region, duplication is evident in approximately a 52-kb region from H2-Q4 to -Q10 (Figure $1 \mathrm{~B}$ left). A long diagonal line is also seen in the H2-T region (Figure 1B right) indicating a multigenic duplication event within the H2-T region from $H 2-T 23$ to $-T 5$ (Figure 2). The phylogenetic tree of H2-T genes (Figure 1C) supports the occurrence of a multigenic duplication event that produced some gene sets with a high sequence similarity ( $>85 \%$ in coding region, e.g. H2-T11 and -T23, H2-T9 and -T15, H2-T1O and -T22, and H2-T5, -T7 and T13). Similarities between these genes are seen not only in the coding region, but also in the untranslated region, introns and intergenic regions (Figures $1 \mathrm{~B}$ and 3 ), indicating the possibility that these genes have a redundant function and/or expression pattern.

Figure 2 shows a schematic representation of a single multigenic tandem duplication of four ancestral genes that generated eight genes within the genomic D1 and D2 duplication products. The model also shows that before the occurrence of the multigenic duplication event a single monogenic tandem duplication had probably generated a copy of the H2-T5 gene. This parsimonious model helps to explain the gene organization (Figure 1B), phylogenetic topologies of the gene sequences (Figure 1C) and the sequence similarities (Figure 3 ) between $\mathrm{H} 2-\mathrm{T} 23$ and T11, H2-T22 and -T10, H2-T15 and -T9, and H2-T13 and -T7. However, the multigenic duplication model presented here for the mouse $\mathrm{H} 2-\mathrm{T}$ region has not taken into account the presence of pseudogenes $T 1$ and $T 2$ and other evolutionary mechanisms that may have contributed to diversity within this region, such as gene conversions and unequal cross-overs with other haplotypes. Nevertheless, the multigenic duplication model for the mouse H2-T region is similar to the multigenic tandem duplication models previously proposed for the Mhc class I region of human and non-human primates $[28,29]$. 

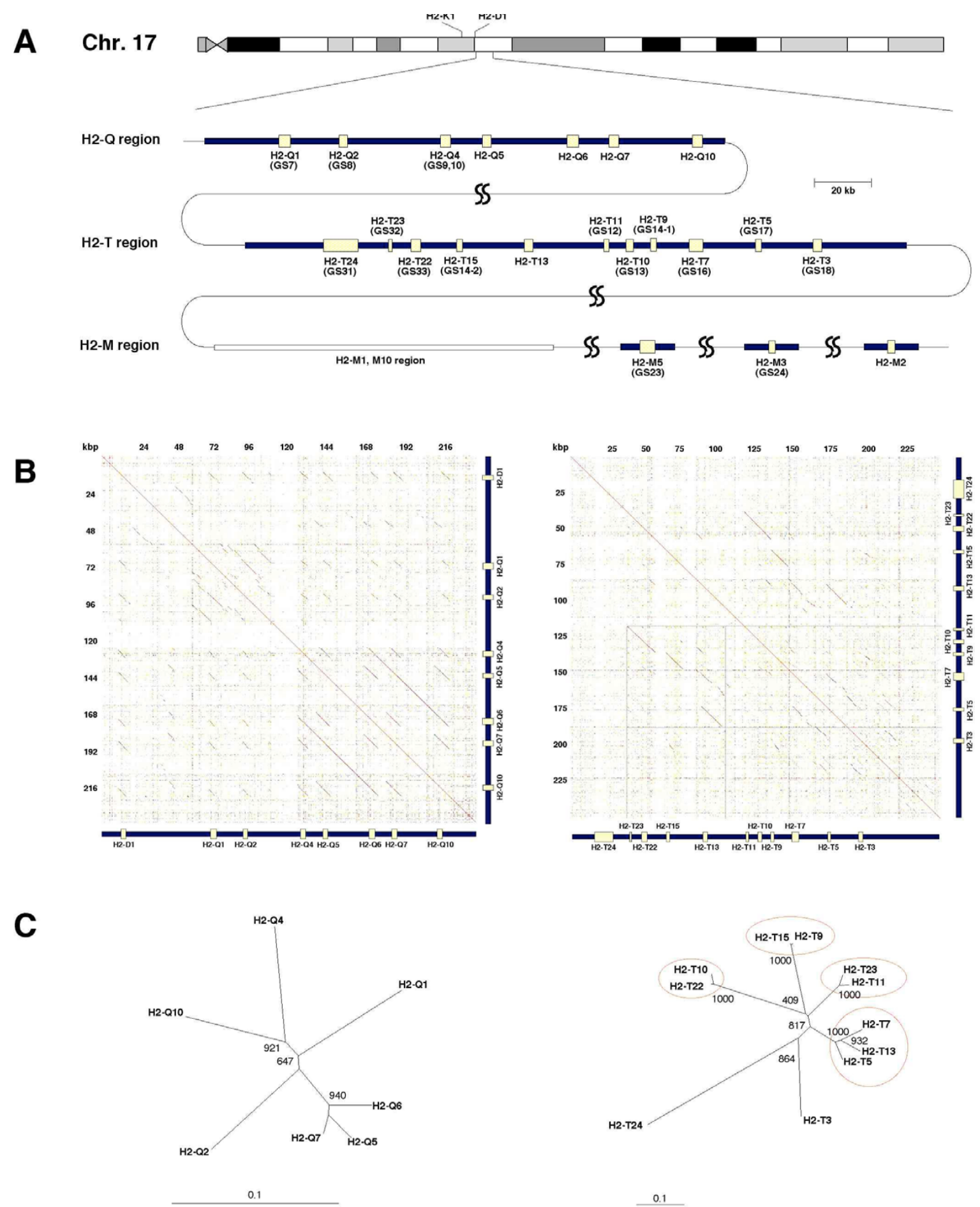

Figure I

Genomic organization of the $\mathbf{H 2}-\mathrm{Q},-\mathbf{- T}$ and $-\mathbf{M}$ region. (A) Gene content of the $H 2-Q,-T$ and $-M$ regions on chromosome 17 of mouse C57BL/6 strain. The Mhc class lb genes with coding potential are represented by yellow boxes. The genes determined by our initial analysis using GENSCAN program are indicated with a GS number. Gene contents regarding $H 2-M I$ and $-M / O$ families were omitted in this figure. The regions indicated by the squiggles are the regions where the non-Mhc genes are interspersed. The scale bar indicating $20 \mathrm{~kb}$ applies to the $H 2-Q$ and $-T$ regions. (B) Dot-plot

comparisons of the mouse $\mathrm{H} 2-Q$ (left) and $-T$ (right) regions. Comparison of the sequence to itself reveals the duplicated regions. (C) Phylogenetic tree analysis of $\mathrm{H2} 2 \mathrm{Q}$ (left) and $-\mathrm{T}$ (right) genes based on nucleotide sequences of the entire coding region. Gene pairs showing highly similar sequences (>85\%) in $\mathrm{H} 2-\mathrm{T}$ region are represented by red circles. Bootstrap values (1000 replicates) are indicated. A scale bar of "0.I" represents a branch-length of 0.1 nucleotide substitutions per site. 
Table I: List of gene specific primer sets used for expression pattern analysis

\begin{tabular}{|c|c|c|c|}
\hline \multirow[t]{2}{*}{ Gene } & \multicolumn{2}{|l|}{ Primer set } & \multirow[t]{2}{*}{ Size (bp) } \\
\hline & Forward & Reverse & \\
\hline $\mathrm{H} 2-\mathrm{KI}$ & GGGAGCCCCGGTACATGGAA & GGTGACTTTATCTTCAGGTCTGCT & 548 \\
\hline$H 2-D I$ & TCGGCTATGTGGACAACAAGG & GGCCATAGCTCCAAGGACAC & 818 \\
\hline$H 2-Q I$ & CTGCGGTATTTCGAGACCTCG & GGTATCTGTGGAGCCACATCAG & $502 / 686$ \\
\hline$H 2-Q 2$ & ACACACAGGTCTCCAAGGAA & TGGATCTTGAGCGTAGTCTCTTA & 785 \\
\hline$H 2-Q 4$ & CTTGCTGAGTTATTTCTACACCT & ACCGTCAGATCTGTGGTGACAT & 583 \\
\hline H2-Q5 & GGGAGCCCCGGTTCATCATC & CAGGGTGACAGCATCATAAGATA & 539 \\
\hline H2-Q6 & GTATTTCCACACTGCTGTGTCCT & AAGGACAACCAGAATAGCTACGT & 871 \\
\hline$H 2-Q 7$ & CGGGCCAACACTCGCTGCAA & GTATCTGCGGAGCGACTGCAT & 515 \\
\hline$H 2-Q 10$ & CACACTCCATGAGGTATTTCGAA & CAGATCAGCAATGTGTGACATGATA & $590 / 866$ \\
\hline $\mathrm{H} 2-\mathrm{T} 24$ & ATGCACAGTACTTCACTCATG & CССCTAGCATATACTCСTGTCG & $736 / 839$ \\
\hline H2-T23 & AGTATTGGGAGCGGGAGACTT & AGCACCTCAGGGTGACTTCAT & 438 \\
\hline $\mathrm{H} 2-\mathrm{T} 22$ & CTGGAGCAGGAGGAAGCAGATA & CAAATGATGAACAAAATGAAAACCA & 698 \\
\hline H2-TIS & ACCGCCCTGGCCCCGACCCAA & CATCCGTGCATATCCTGGATT & 332 \\
\hline $\mathrm{H} 2-\mathrm{T} / 3$ & GCCCTGACTATGATCGAGACT & CACCTCAGGGTGACATCACCTG & 635 \\
\hline H2-TII & CGGTATTTCCACACCGTCGTA & TAGAGATATGCGAGGCTAAGTTG & $415 / 628$ \\
\hline $\mathrm{H} 2-\mathrm{TIO}$ & CCCTTTGGGTTCACACTCGCTT & CCTGGTCTCCACAAACTCCACTTCT & 661 \\
\hline H2-T9 & ACCGCCCTGGCCCCGACCCGA & CATCCGTGCATATCCTGGATA & 332 \\
\hline H2-T7 & CTTCACACGTTCCAGCTGTTGTT & AGGCCTGGTCTCCACAAGCTCT & 432 \\
\hline H2-T5 & GGTGGTGTTGCAGAGACGCT & CTGCTCTTCAACACAAAAGG & 482 \\
\hline H2-T3 & TTCAACAGCTCAGGGGAGACTG & AAGCTCCGTGTCCTGAATCAAT & 585 \\
\hline H2-M3 & CAGCGCTGTGATAGCATTGA & ACAACAATAGTGATCACACCT & 806 \\
\hline $\mathrm{H} 2-\mathrm{M} 2$ & GAGGAGACCCACTACATGACTGTT & GAAAATGAAAGACTGAGGAGGTCTAC & 798 \\
\hline$b 2 m^{*}$ & ATGGCTCGCTCGGTGACCCTG & ATTGCTCAGCTATCTAGGATA & 546 \\
\hline GAPDH* & TGAAGGTCGGTGTGAACGGATTTG & GGCCTTCTCCATGGTGGTGAAGAC & 314 \\
\hline
\end{tabular}

*Sequences of these primers were obtained from a previous report [25].

Regarding the $H 2-Q$ region, the genes $H 2-Q 5,-Q 6$ and Q7, which form a tandem array in the $H 2-Q$ region (Figure $1 \mathrm{~B})$, also grouped relatively closely together in the phylogenetic tree analysis (Figure 1C). Assuming the current genome assembly is correct, then these three genes were probably generated by two separate monogenic tandem duplications much more recently than the duplications previously involved with the generation of the $\mathrm{H} 2$ Q1,-Q2,-Q4 and -Q10 genes, which are more distantly related in sequence in the phylogenetic analysis. However, the duplication structure of the $H 2-Q$ region in $\mathrm{C} 57 \mathrm{BL} / 6$ (Figure 1B left) appears to be different to the mouse strain $129 /$ SvJ [30].

\section{Expression of Mhc class lb genes in adult tissues}

To clarify the tissue expression patterns for each of the Mhc class Ib genes, we conducted RT-PCR analysis of the cDNAs isolated from various tissues of the adult mouse. Although it is difficult to analyze Mhc class I expression due to the sequence similarity of the Mhc genes (showing $60-95 \%$ identities in coding region; data not shown), we circumvented this disadvantage by designing the genespecific primer sets that are listed in Table 1. Transcription of each Mhc class I gene was detected as shown in Figure 4. The gene identities of the amplified cDNAs were confirmed by direct sequencing of the RT-PCR-amplified frag- ments (indicated by yellow asterisks in Figure 4). Using the specific primer sets, we successfully amplify most of the identified Mhc class Ib genes, except for H2-M5, which may be expressed at very low levels and below the limit of detection of our RT-PCR assays. We obtained amplified fragments of the H2-M5 gene from the brain and thymus, but we were unable to detect amplified products in the other tissues (data not shown).

The gene expression patterns were classified into two types: tissue-wide or tissue-specific expression. H2-Q4, Q7, -T24, -T23, -T22 and -M3 as well as the class Ia genes (H2-K1 and -D1) exhibited tissue-wide expression. In contrast, H2-Q1, -Q2, -Q5, -Q6, -Q10, -T15, -T13, -T11, -T10, $-T 9,-T 7,-T 5,-T 3$ and $-M 2$ genes were expressed in a tissuespecific manner. Regardless of the tissue-wide or tissuespecific expression patterns, most of the class I genes were expressed in the thymus and intestine, both of which are critical organs for immune defense.

The tissue expression patterns of the genes H2-T11 and T10 located within the duplicated D2 region (Figure 2) are more tissue-restricted than those of the respective paralogous genes H2-T23 and -T22 (Figures 4 and 5) that are located within the duplicated D1 region (Figure 2), confirming that major changes do occur in the expression 
Table 2: List of mouse MHC class lb genes analysed in this study

\begin{tabular}{|c|c|c|c|c|}
\hline \multicolumn{2}{|c|}{ Gene name } & \multicolumn{3}{|c|}{ mRNA sequences referred } \\
\hline Used in this study & Others & $\mathrm{NCBI}$ accession & Ensembl transcript ID & $\mathrm{NCBI}$ accessions determined in this study \\
\hline QI (GS7) & & U96752 & ENSMUST00000073208 & - \\
\hline Q2 (GS8) & & AY989880 & ENSMUST00000074806 & AB266872 \\
\hline Q4 (GS9,10) & Qb-I & XR_034205 & ENSMUST00000 I I 3887 & $A B 267092, A B 266873$ \\
\hline Q5 & & - & ENSMUST00000040240 & - \\
\hline Q6 & & NM_207648 & ENSMUST00000091611 & - \\
\hline Q7 & Qa-2, Ped & NM_010394 & ENSMUST0000007I95। & - \\
\hline Q10 & & AKI3I620 & ENSMUST0000006829I & - \\
\hline T24 (GS3I) & & NM_008207 & ENSMUST00000066488 & - \\
\hline T23 (GS32) & Qa-I & & ENSMUST00000102678 & $A B 359230$ \\
\hline T22 (GS33) & & AKI 33985 & ENSMUST0000005880 I & AB359229 \\
\hline TI5 (GSI4-2) & & - & ENSMUST00000II 3742 & AB359227 \\
\hline TI3 & $\mathrm{BI}$, blastocyst MHC, T25 & AY98982I & ENSMUST00000025333 & - \\
\hline $\mathrm{TII}(\mathrm{GSI})$ & & XM_975970 & ENSMUST00000079918 & - \\
\hline TIO (GSI3) & & NM_010395 & ENSMUST0000007420I & - \\
\hline T9 (GSI4-I) & & - & - & AB267093 \\
\hline T7 (GSI6) & & NM_001025208 & ENSMUST00000064686 & - \\
\hline T5 (GSI7) & & NM_00I08I032 & ENSMUST00000040467 & AB35923I \\
\hline T3 (GSI8) & TL & AK033602 & ENSMUST000000253 I 2 & - \\
\hline M5 (GS23) & CRW2 & XM_903477 & ENSMUST00000II 3667 & $A B 359228$ \\
\hline M3 (GS24) & $\mathrm{Hmt}$ & NM_013819 & ENSMUST00000038580 & AB267096 \\
\hline M2 & Thy 19.4 & AY302212 & ENSMUST00000077662 & - \\
\hline
\end{tabular}

Haplotype b (C57BL/6) was used. Nomenclature of each gene was based on the previous reports [23, 26], except for GS number. The H2 prefixes were omitted. The GS numbers in parenthesis represent the gene sequence numbers used in our laboratory.

profiles and functions of recently duplicated genes. Of particular note is the loss of expression in the liver, heart, muscle and testis by H2-T11, as previously reported for the liver [31], in comparison to its paralogous gene, $\mathrm{H2}$ T23; and the loss of expression of H2-T10 in all tissues except the thymus, spleen, ovary and placenta in comparison to the tissue-wide expression by its paralogous gene H2-T22. The gene paralogs, H2-T13, -T7 and -T5, all showed tissue specific expression in the small intestine, except that the brains of adults also expressed the H2-T13 gene, the thymus and placenta expressed the H2-T5 gene and the thymus, ovary and placenta expressed H2-T7 (Figure 4).

The tissue expression patterns of the two flanking genes, H2-T24 and -T3, in the H2-T region are markedly different and may be among the oldest of the genes in this region. The centromeric H2-T24 gene was expressed widely, whereas the telomeric H2-T3 gene expression was restricted to the thymus and the small intestine (Figure 4) as previously reported $[12,13]$.

As described above, the genes H2-Q5, -Q6 and -Q7 were probably generated by monogenic tandem duplications. In this regard, H2-Q7 showed the widest tissue expression, followed by H2-Q6 and then H2-Q5. This suggests that there might have been a gain or loss of tissue specificity with each gene duplication event. Of the other $H 2-\mathrm{Q}$ genes, the most tissue-wide expression was by H2-Q4.

The Mhc gene expression in the brain is of particular interest because such genes could have a specific function in brain development and plasticity [17]. In this study, we identified 12 class Ib genes, H2-Q1, -Q2, -Q4, -Q7, -T24, T23, -T22, -T15,-T13,-T11, -M3 and -M5, expressed in the brain. The Mhc gene expression in the brain warrants further investigation particularly to determine in what cells (neurons and/or various glial cells) and at what stages of brain development these genes are expressed.

Expression of Mhc class lb genes in embryos and placentas Some Mhc genes are known to express and function during development in the embryo $[32,33]$ and/or in the placenta [34]. Therefore, we determined which of the 20 class Ib genes were expressed in the embryo and placenta (Figure 4 and 5). The expression of some of the class Ib genes gradually increased (e.g. H2-Q10 and -T7) or decreased (e.g. H2-Q6 and -M3) during the course of development. The class Ib genes that were expressed widely in the adult tissues (H2-Q4, -Q7, -T24, -T23, -T22 and -M3) also tended to be expressed throughout the developmental stages. This observation suggests that the regions in which these class Ib genes are located may have an open or accessible chromatin configuration from the time of the first 


\section{Expansion of $H 2-T$ region by monogenic and multigenic tandem duplications}

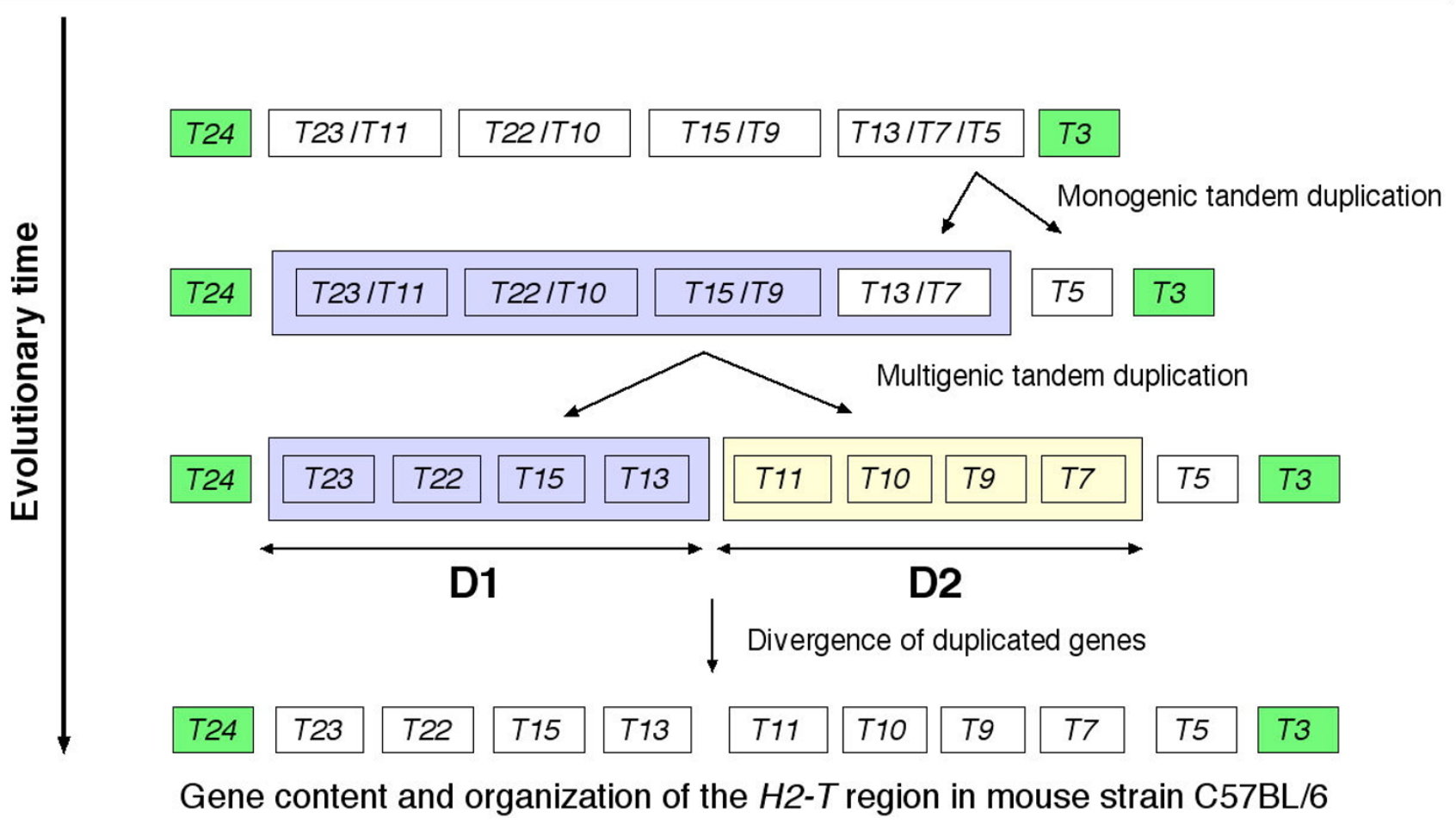

Figure 2

A schematic model of the expansion of the $\mathrm{H2}-\mathrm{T}$ region by monogenic and multigenic tandem duplications. This model represents monogenic and multigenic tandem duplications originating from a hypothetical ancestral $H 2-T$ genomic sequence consisting of six $\mathrm{H} 2-\mathrm{T}$ genes. Each labeled box represents a $\mathrm{H} 2-\mathrm{T}$ gene in a linear array (horizontal) at different evolutionary times along the vertical axis. The horizontal double arrows labeled DI and D2 represent the genomic products of the multigenic tandem duplication, with each product consisting of four genes.

observable developmental stage. We could not detect $H 2$ T13, $-T 10,-T 9,-T 3$ and $-M 2$ in the embryo or placenta, although H2-T13 (Blastocyst MHC) was previously shown to express in the placenta of B6 mice [34]. This negative result may be due to the developmental stage examined. Tajima et al. (2003) examined Blastocyst MHC gene expression at E3.5, E7.5 and E13.5 and expression at E13.5 was difficult to detect [34], while we analyzed gene expression at the developmental stages from E9.5 - E14.5.

We also examined the expression of class Ib genes in the brains of the E14.5 embryos (Figure 5). Nine genes (H2Q1,-Q2,-Q4,-Q7,-T24,-T23,-T22,-T11 and -M3) were transcribed in the brains of the E14.5 embryos. All of them were also expressed in the adult brain (Figure 4), indicating that these gene products may have a functional role in both adult and embryonic brains.

From the RT-PCR analyses in Figure 4 and 5, we identified alternative splicing variants in the H2-Q1, -Q10, -T24, T11, -T9 and -M5 (for M5 gene, see GenBank:AB378579) genes. The splicing patterns can be classified into four types: A) a common splicing pattern for class I gene, B) a loss of alpha2 domain, C) an unspliced second intron and D) an unspliced fourth intron. The type $B$ variant was seen for H2-Q10 and -M5 expression, whereas type $\mathrm{C}$ was observed in H2-Q1, -T11 and -T9 expression. H2-T24 showed type $\mathrm{D}$ variant. It is of interest in future to determine whether these splicing variants have distinct or common functions. The type $\mathrm{A}$ and type $\mathrm{B}$ variants were previously reported for the H2-T13 (Blastocyst MHC) gene, and the RMA-S cell expressing the type B variant was protected from NK cell-mediated rejection via loading of its signal peptide onto the Qa-I molecules [34].

\section{Expression patterns between duplicated class lb genes}

Since local duplication in the $\mathrm{H} 2-\mathrm{T}$ region (Figure 2 ) have produced gene sets with high sequence similarity (Figures $1 \mathrm{~B}, \mathrm{C}$ and 2) even in the upstream promoter region (Figure 3), a redundant expression pattern was expected between the similar genes. However, as described above, the expression patterns between similar genes were mostly 

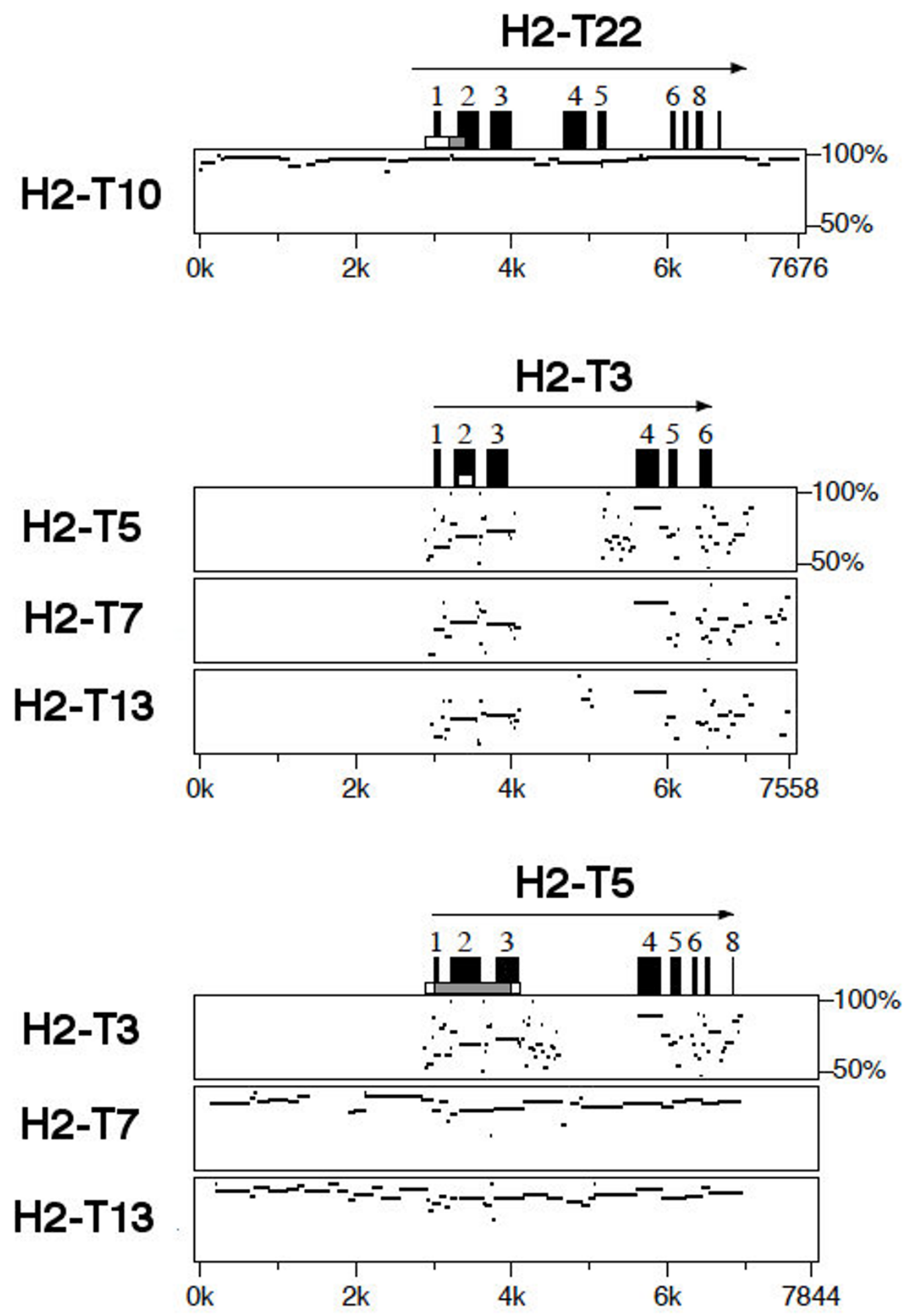

Figure 3

PipMaker analyses of genomic sequences of mouse H2-T genes. PipMaker analyses were performed to detect similarity within the promoter region. Sequences used for comparison include $3 \mathrm{~kb}$ of 5' upstream region and I kb of 3' downstream region of coding sequence for each gene. Exons are indicated by black boxes above the plot. 


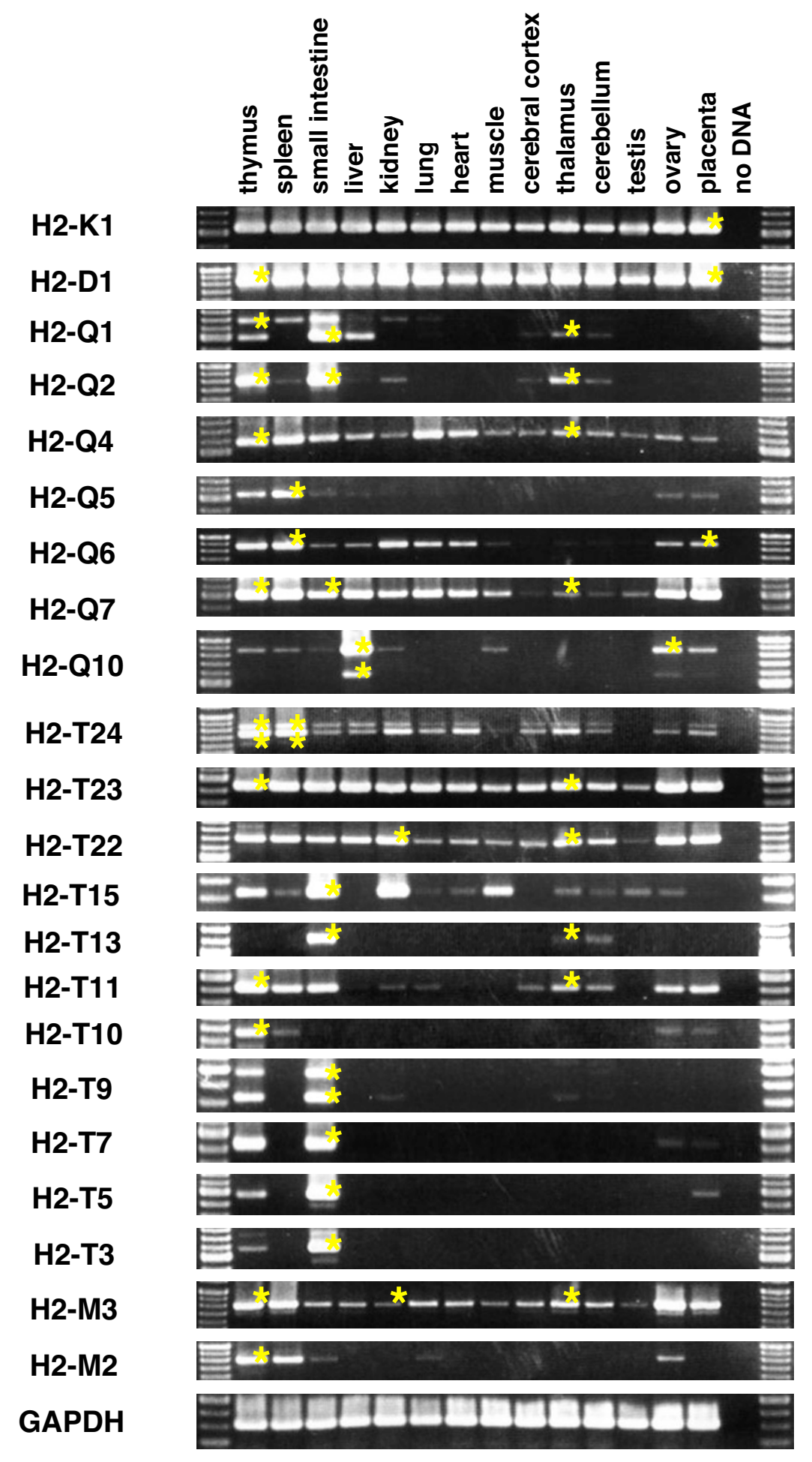

Figure 4

Expression of Mhc class lb genes in adult tissues. RT-PCR was performed on total RNA isolated from tissues of C57BL/ 6J mouse. Identities of bands were confirmed by amplified sizes and by sequencing (indicated by yellow asterisk). The same reaction conditions were used for PCR. 


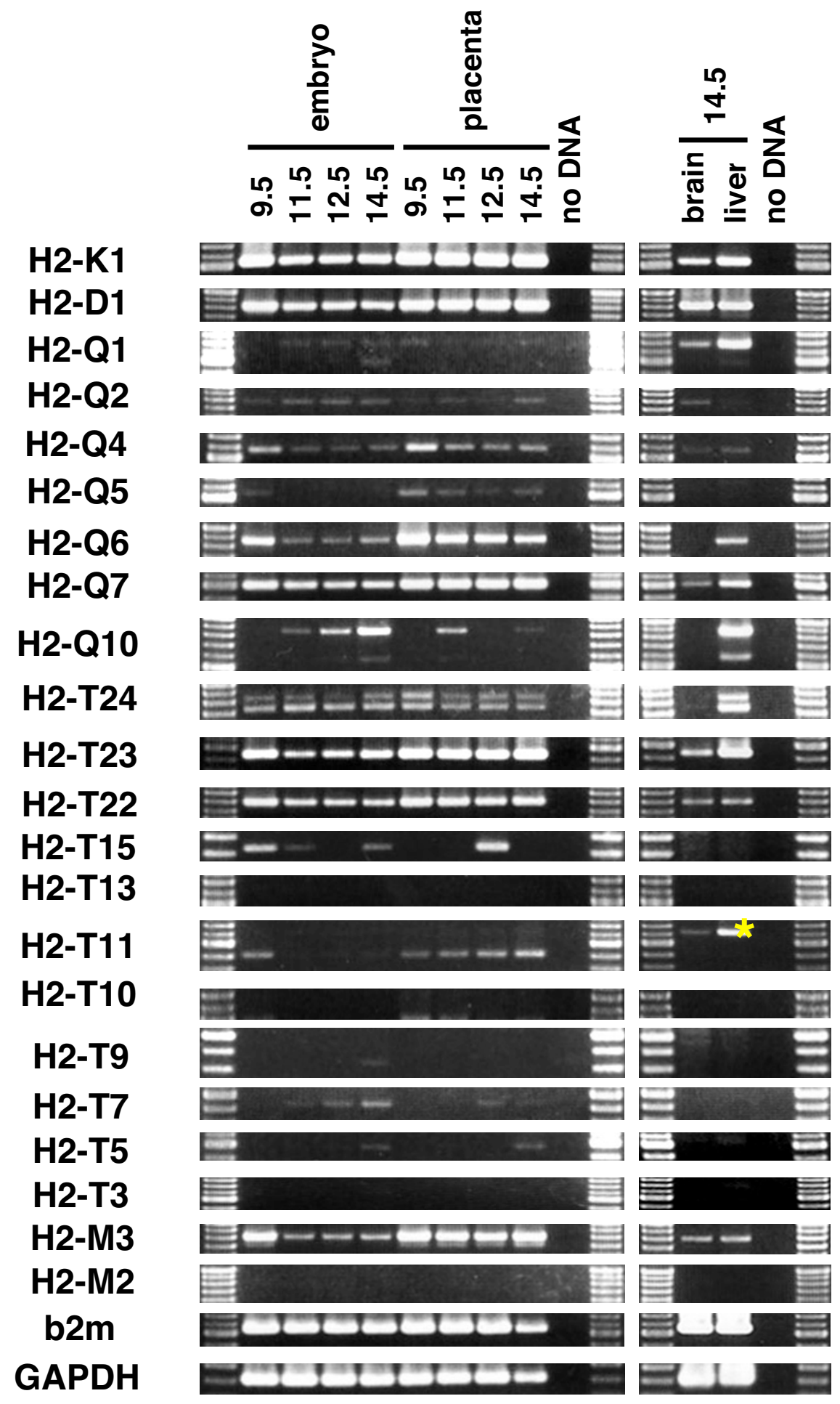

Figure 5

Embryonic and placental expression of Mhc class Ib genes. RT-PCR analysis was performed on total RNA isolated from E9.5-14.5 of C57BL/6) embryos and placentas. As for the EI4.5 embryo, RT-PCR was conducted using CDNA as templates, derived from total RNA isolated from the brain and liver. Identities of bands were confirmed by amplified sizes and by sequencing (indicated by yellow asterisk). The same reaction conditions were used for PCR. 
different. For example, H2-T23 was expressed widely, whereas the H2-T11 gene paralog showed a much more restricted expression pattern. This difference in expression between duplicated genes was especially remarkable for H2-T22 and -T1O expression (Figure 4) because the sequences of the upstream promoter regions of H2-T22 and $-T 10$ are almost identical (Figure 3 ). In contrast, the H2-T13, -T5 and - T7 duplicated genes have similar nucleotide sequences, including within their promoter region, and similar expression patterns (predominantly in small intestine). This expression pattern, especially for H2-T5 and $-\mathrm{T} 7$, was almost the same as for H2-T3 that flanks these genes (Figure 2), but exhibited no similarity in the promoter sequence (Figure 3 ).

The co-expression of neighboring genes, such as H2-T24 to -T22 or H2-T15 to -T3 (Figure 2), may be regulated by 1) independent cis-acting regulatory elements for each gene that produce similar expression patterns, or by 2) a shared long-range regulatory element that operates over several genes (i.e. a long-range enhancer and/or a chromatin level regulation). Model 1 is appropriate for duplicated regions in which control regions are duplicated together with the coding sequence [35]. This is the most likely explanation for co-expression of $\mathrm{H} 2-\mathrm{T} 5$ and $-\mathrm{T} 7$ (Figure 3 ). The possibility that different promoter sequences produce a similar expression pattern might also be explained by model 1 . The $2.8 \mathrm{~kb}$ promoter region of H2-T3 was shown previously to direct transgene expression in the epithelial cells of the small and large intestine [36]. Therefore, it will be of interest in future to examine whether the upstream regions of $\mathrm{H} 2-\mathrm{T} 5$ and -T7 have the same activity as that of H2-T3 (Figure 3). We think, however, it is unlikely that all the genes located between H2-T24 to -T22 or H2-T15 to T3 contain their own cis-regulatory element with similar function. Considering the order of the H2-T genes that show tissue-wide or tissue-specific expression, we rather favor model 2 . The H2-T genes with tissue-wide expression are located within the same $40 \mathrm{~kb}$ centromeric portion of the H2-T region (H2-T24 to -T22), whereas the genes H2-T15 to -T3 located at the telomeric-end exhibited a tissue-specific expression pattern with most of them predominantly expressed in the small intestine (Figure 4). The region containing the genes from $\mathrm{H2}-\mathrm{T1} 15$ to $-\mathrm{T3}$ with the restricted tissue expression spans as much as $150 \mathrm{~kb}$, which is consistent with the possibility of a long-range regulation. The long-range regulation may provide a simple explanation of different expression patterns of similar genes (e.g. H2-T22 and -T10) and similar expression pattern of genes with distinct promoter regions (e.g. H2-T5, T7 and -T3) over long distances. This model is supported by recent papers that reported that a special AT-rich binding protein 1 (SATB1), the most characterized matrix attachment regions (MARs)-binding protein (MBP), is involved in the tissue-specific chromatin organization of the human $M H C$ class I locus and its expression profile $[37,38]$.

The mouse is known to have strain-specific gene duplications in the H2- $\mathrm{T}$ region with a number of duplicated $\mathrm{H2}$ $T$ gene differences between strains producing considerable variability between haplotypes $[39,40]$. The genomic features, organization and the expression patterns of the H2$T$ genes in other mouse strains warrant a comparative analysis. The expression pattern analysis of rat Mhc class Ib genes [41] may also provide clues for our hypothesis for the long-range regulation of duplicated class Ib gene expression. In addition, an investigation of gene duplications in genetically modified mice may help to distinguish between the different models involved in the regulation of duplicated gene expression. We are currently generating chromosomally engineered mice towards these ends.

\section{Conclusion}

We have identified 21 transcribed Mhc class Ib genes in the $H 2-Q,-T$ and $-M$ regions and examined their expression patterns within a wide array of developmental and adult mouse tissues. Some of the class Ib gene products were expressed tissue-wide, while others were expressed in a tissue-restricted manner. These results provide a basis to select important candidate $\mathrm{Mhc}$ class Ib genes for future functional validation studies. For example, we found 12 brain-expressed class Ib genes that could have neuronal and other functions in brain development and plasticity. We also found that genes expressed tissue-wide are located in the centromeric region, whereas the tissue-specifically expressed genes are located towards the telomeric end of the H2-T region where the number of genes has been increased by local duplication. In this region, there are genes that showed distinct expression patterns in spite of their similar nucleotide sequences, and there is a gene pair that has a similar expression pattern, but dissimilar promoter sequence regions. From these results, the presence of a long-range regulation of $\mathrm{H} 2-\mathrm{T}$ genes is suggested, although we cannot dismiss the possibility that nucleotide changes in the promoter and enhancer regions have contributed to the loss or gain of tissue-wide expression. Since this region has diversified not only between rodent species, but also between mouse strains, it should be a good model region to address the relationship between genomic organization and expression patterns.

\section{Methods}

\section{Sequence analysis}

The genomic sequences of the $\mathrm{H} 2$ region used in this study were obtained from the public databases at the NCBI Entrez Genome Project ID 9559 [42] and the Ensembl Mouse Genome Project [43]. Although we first analyzed the NT_039650.2 genomic contig by using a GENSCAN program [44] to identify the Mhc class Ib 
genes, we finally utilized the NCBI Mouse Build 36 containing the nearly completely annotated sequence of this region, which was released on June $20^{\text {th }}, 2006$. Dot matrix analysis was performed on these genomic sequences to detect duplicated regions by using Harrplot Ver. 2.0 as part of the computer software GENETYX package. Complete or partial coding sequences of each $M h c$ class I gene was first predicted by GENSCAN, referred to the annotation, and finally confirmed by the sequencing of RT-PCR products. These coding sequences (nucleic acids) were aligned by the ClustalW program version 1.83 at DDBJ [45] using the default setting and Kimura's two-parameter method to estimate the evolutionary distances. The final outputs as radial phylogenetic trees were generated with the TreeView drawing software. The sequences used for the phylogenetic tree analyses are listed in Table 2 (shown in "Ensembl transcript ID" column for H2-Q1, -Q2, -Q5, Q6, -Q7, -Q10, -T24, -T13, -T11, -T10, -T7 and -T3, in "NCBI accession" column for H2-Q4, and in the "Determined in this study" column for H2-T23, -T22, -T15, -T9, -T5). PipMaker analyses were performed on selected Mhc class Ib gene sequences to visualize the DNA sequence similarities [46]. The genomic sequences analyzed by PipMaker contained the regulatory region $3 \mathrm{~kb}$ upstream from ATG start codon and the untranslated downstream region $1 \mathrm{~kb}$ from the stop codon in addition to the exon and intron sequences.

\section{Reverse transcriptase-polymerase chain reaction (RT- PCR)}

The mRNA expression of Mhc class Ib genes was determined by RT-PCR analysis. Total cellular RNA was isolated from the thymus, spleen, small intestine, liver, kidney, lung, heart, skeletal muscle, cerebral cortex, thalamus, cerebellum, testis and ovary of adult C57BL/6J mice, and the embryo (E9.5 - E14.5, where embryonic day 0.5 [E0.5] was defined as midday (noon) of day 1 when a vaginal plug was detected after overnight mating.), placenta (E9.5 - E14.5), and embryonic (E14.5) brains and livers of $\mathrm{C} 57 \mathrm{BL} / 6 \mathrm{~J}$ mice using the guanidine isothiocyanate/ $\mathrm{CsCl}$ ultracentrifugation method. Complementary DNA (cDNA) was synthesized from isolated RNA using the Gene Amp RNA-PCR core kit (Applied Biosystem) with the oligo-dT primer and $2 \mu \mathrm{g}$ RNA as template in a $40 \mu \mathrm{l}$ volume according to the manufacture's protocol. An aliquot of $0.5 \mu$ l from the $40 \mu$ l of the cDNA was used for RTPCR reactions of all cDNA samples. The PCR was performed in $20 \mu \mathrm{l}$ of a total reaction volume under the following conditions: cDNA was denatured at $95^{\circ} \mathrm{C}$ for 5 min, followed by 35 cycles of amplification $\left(95^{\circ} \mathrm{C}\right.$ for 45 $\mathrm{s}, 58^{\circ} \mathrm{C}$ for $30 \mathrm{~s}$ and $72^{\circ} \mathrm{C}$ for $1 \mathrm{~min}$ ) and $5 \mathrm{~min}$ at $72^{\circ} \mathrm{C}$. The PCR primers used for the amplifications are listed in Table 1 (see also additional file 1). The primer sets were manually designed to amplify specific Mhc class Ib genes by locating the gene specific polymorphisms within 5-bp of the 3' end as much as possible. All primers were designed within putative cDNA to flank or cross at least one exon-intron border. Resultant RT-PCR products were directly sequenced to verify their identity.

\section{3' Rapid amplification of CDNA end (RACE) and cloning of class Ib cDNAs}

To determine the complete cDNA sequences of H2-T5, T15, -T22, -T23 and -M5, 3'RACE was performed using thymus or duodenum RNAs as template, the oligo-dTprimer with adapter (GGCCACGCGTCGACTAGTACT ${ }_{17}$.), and the forward primers listed in Table 1. The 3'RACE products were cloned into pBSII plasmid (STRATAGENE). RT-PCR covering the translation start site was done using the following forward primers designed from the genomic sequences around the translation start codon (ATG) as predicted by GENSCAN program:

\section{H2-T5; TCTCCTGTATCATCATTCCCAGAT,}

\section{H2-T15; ACTGTACTGAGCTCTCTCTATCCCA,}

\section{H2-T22; AGTTTATAAAGCTGTCCAAGATCT,}

\section{H2-T23; GATTCAGGTTCCTCACAGACCCAG,}

H2-M5; TGTATGAGAAGCCCTGCGCTCT, and the reverse primer listed in Table 1. The products were also cloned into pBSII plasmid. The nucleotide sequences of the 3'RACE and RT-PCR products were combined and analyzed.

\section{List of abbreviations}

Mhc: major histocompatibility complex; RT-PCR: Reverse transcriptase-polymerase chain reaction.

\section{Authors' contributions}

MO designed and performed the experiments, conducted genome analyses, prepared the manuscript, and is responsible for this study. HI is the director of the laboratory and gave suggestions for this study. JKK helped in editing the manuscript and in interpreting the genome analysis. SY carried out the preparation, cloning and sequencing of cDNA, and participated in the design of the study. All authors have read and approved the final manuscript.

\section{Additional material}

\section{Additional file 1}

Primer positions. Positions of primers were indicated in alignment of Mhc class I sequences. Forward and reverse primers were shown in red and blue, respectively.

Click here for file

[http://www.biomedcentral.com/content/supplementary/1471-

2164-9-178-S1.doc] 


\section{Acknowledgements}

We thank A. Shigenari, H. Miura, M. Koshimizu and M. Ayabe for technical assistance. We also thank reviewer 3 for his suggestion regarding nomenclature of $\mathrm{H} 2$ genes. This work was supported in part by the Research and Study Program of the Tokai University Educational System General Research Organization (2005), and by 2006 Tokai University School of Medicine Research Aid to MO.

\section{References}

I. Snell GD: The Nobel Lectures in Immunology. Lecture for the Nobel Prize for Physiology or Medicine, 1980: Studies in histocompatibility. Scand J Immunol I992, 36(4):5। 3-526.

2. Zinkernagel RM, Doherty PC: The discovery of MHC restriction. Immunol Today 1997, I8(I): I4-17.

3. Kumanovics A, Fischer Lindahl K: Good copy, bad copy: choosing animal models for HLA-linked diseases. Curr Opin Genet Dev 2004, I 4(3):258-263.

4. Cresswell P, Ackerman AL, Giodini A, Peaper DR, Wearsch PA: Mechanisms of MHC class I-restricted antigen processing and cross-presentation. Immunol Rev 2005, 207:145-157.

5. Shen L, Rock KL: Priming of $\mathbf{T}$ cells by exogenous antigen cross-presented on MHC class I molecules. Curr Opin Immunol 2006, I 8(I):85-9I.

6. Smyth LA, Afzali B, Tsang J, Lombardi G, Lechler RI: Intercellular transfer of MHC and immunological molecules: molecular mechanisms and biological significance. Am J Transplant 2007, 7(6): $1442-1449$

7. Stroynowski I, Lindahl KF: Antigen presentation by non-classical class I molecules. Curr Opin Immunol I994, 6(I):38-44.

8. Hu D, Ikizawa K, Lu L, Sanchirico ME, Shinohara ML, Cantor H: Analysis of regulatory CD8 T cells in Qa-I-deficient mice. Nat Immunol 2004, 5(5):516-523.

9. Sarantopoulos S, Lu L, Cantor H: Qa-I restriction of CD8+ suppressor T cells. J Clin Invest 2004, I | 4(9): | 2 I8- 22 I.

10. Lu L, Werneck MB, Cantor $\mathrm{H}$ : The immunoregulatory effects of Qa-I. Immunol Rev 2006, 21 2:5।-59.

II. Xu H, Chun T, Choi HJ, Wang B, Wang CR: Impaired response to Listeria in $\mathrm{H} 2-\mathrm{M} 3$-deficient mice reveals a nonredundant role of MHC class Ib-specific T cells in host defense. J Exp Med 2006, 203(2):449-459.

12. Madakamutil LT, Christen U, Lena CJ, Wang-Zhu Y, Attinger A, Sundarrajan M, Ellmeier W, von Herrath MG, Jensen P, Littman DR, Cheroutre H: CD8alphaalpha-mediated survival and differentiation of CD8 memory $\mathbf{T}$ cell precursors. Science 2004, 304(5670):590-593.

13. Leishman AJ, Naidenko OV, Attinger A, Koning F, Lena CJ, Xiong Y, Chang $H C$, Reinherz E, Kronenberg $M$, Cheroutre $H: T$ cell responses modulated through interaction between CD8alphaalpha and the nonclassical MHC class I molecule, TL. Science 200I, 294(5548):1936-1939.

14. Loconto J, Papes F, Chang E, Stowers L, Jones EP, Takada T, Kumanovics A, Fischer Lindahl K, Dulac C: Functional expression of murine $V 2 R$ pheromone receptors involves selective association with the MIO and MI families of MHC class Ib molecules. Cell 2003, I I 2(5):607-6I8.

15. Ishii T, Hirota J, Mombaerts P: Combinatorial coexpression of neural and immune multigene families in mouse vomeronasal sensory neurons. Curr Biol 2003, I3(5):394-400.

16. Wu L, Feng H, Warner CM: Identification of two major histocompatibility complex class Ib genes, Q7 and Q9, as the Ped gene in the mouse. Biol Reprod 1999, 60(5): III4-III9.

17. Huh GS, Boulanger LM, Du H, Riquelme PA, Brotz TM, Shatz CJ: Functional requirement for class I MHC in CNS development and plasticity. Science 2000, 290(5499):2155-2I59.

18. Syken J, Grandpre T, Kanold PO, Shatz CJ: PirB restricts oculardominance plasticity in visual cortex. Science 2006, 3 I3(5794): I795-1800.

19. Amadou C, Younger RM, Sims S, Matthews LH, Rogers J, Kumanovics A, Ziegler A, Beck S, Lindahl KF: Co-duplication of olfactory receptor and MHC class I genes in the mouse major histocompatibility complex. Hum Mol Genet 2003, I 2(22):3025-3040.

20. Takada T, Kumanovics A, Amadou C, Yoshino M, Jones EP, Athanasiou M, Evans GA, Fischer Lindahl K: Species-specific class I gene expansions formed the telomeric I $\mathrm{mb}$ of the mouse major histocompatibility complex. Genome Res 2003, I3(4):589-600.

21. Postlethwait J, Amores A, Cresko W, Singer A, Yan YL: Subfunction partitioning, the teleost radiation and the annotation of the human genome. Trends Genet 2004, 20( I 0):48I-490.

22. Waterston RH, Lindblad-Toh K, Birney E, Rogers J, Abril JF, Agarwal P, Agarwala R, Ainscough R, Alexandersson M, An P, Antonarakis SE, Attwood J, Baertsch R, Bailey J, Barlow K, Beck S, Berry E, Birren B, Bloom T, Bork P, Botcherby M, Bray N, Brent MR, Brown DG, Brown SD, Bult C, Burton J, Butler J, Campbell RD, Carninci P, Cawley S, Chiaromonte F, Chinwalla AT, Church DM, Clamp M, Clee C, Collins FS, Cook LL, Copley RR, Coulson A, Couronne O, Cuff J, Curwen V, Cutts T, Daly M, David R, Davies J, Delehaunty KD, Deri J, Dermitzakis ET, Dewey C, Dickens NJ, Diekhans M, Dodge S, Dubchak I, Dunn DM, Eddy SR, Elnitski L, Emes RD, Eswara P, Eyras E, Felsenfeld A, Fewell GA, Flicek P, Foley K, Frankel WN, Fulton LA, Fulton RS, Furey TS, Gage D, Gibbs RA, Glusman G, Gnerre S, Goldman N, Goodstadt L, Grafham D, Graves TA, Green ED, Gregory S, Guigo R, Guyer M, Hardison RC, Haussler D, Hayashizaki Y, Hillier LW, Hinrichs A, Hlavina W, Holzer T, Hsu F, Hua A, Hubbard T, Hunt A, Jackson I, Jaffe DB, Johnson LS, Jones M, Jones TA, Joy A, Kamal M, Karlsson EK, Karolchik D, Kasprzyk A, Kawai J, Keibler E, Kells C, Kent WJ, Kirby A, Kolbe DL, Korf I, Kucherlapati RS, Kulbokas EJ, Kulp D, Landers T, Leger JP, Leonard S, Letunic I, Levine R, Li J, Li M, Lloyd C, Lucas S, Ma B, Maglott DR, Mardis ER, Matthews L, Mauceli E, Mayer JH, McCarthy M, McCombie WR, McLaren S, McLay K, McPherson JD, Meldrim J, Meredith B, Mesirov JP, Miller W, Miner TL, Mongin E, Montgomery KT, Morgan M, Mott R, Mullikin JC, Muzny DM, Nash WE, Nelson JO, Nhan MN, Nicol R, Ning Z, Nusbaum C, O'Connor MJ, Okazaki Y, Oliver K, Overton-Larty E, Pachter L, Parra G, Pepin KH, Peterson J, Pevzner P, Plumb R, Pohl CS, Poliakov A, Ponce TC, Ponting CP, Potter S, Quail M, Reymond A, Roe BA, Roskin KM, Rubin EM, Rust AG, Santos R, Sapojnikov V, Schultz B, Schultz J, Schwartz MS, Schwartz S, Scott C, Seaman S, Searle S, Sharpe T, Sheridan A, Shownkeen R, Sims S, Singer JB, Slater G, Smit A, Smith DR, Spencer B, Stabenau A, Stange-Thomann N, Sugnet C, Suyama M, Tesler G, Thompson J, Torrents D, Trevaskis E, Tromp J, Ucla C, Ureta-Vidal A, Vinson JP, Von Niederhausern AC, Wade CM, Wall M, Weber RJ, Weiss RB, Wendl MC, West AP, Wetterstrand K, Wheeler R, Whelan S, Wierzbowski J, Willey D, Williams S, Wilson RK, Winter E, Worley KC, Wyman D, Yang S, Yang SP, Zdobnov EM, Zody MC, Lander ES: Initial sequencing and comparative analysis of the mouse genome. Nature 2002, 420(69 I5):520-562.

23. Weiss EH, Golden L, Fahrner K, Mellor AL, Devlin JJ, Bullman H, Tiddens $\mathrm{H}$, Bud $\mathrm{H}$, Flavell RA: Organization and evolution of the class I gene family in the major histocompatibility complex of the C57BL/I 0 mouse. Nature 1984, 3 I 0(5979):650-655.

24. Brown GD, Choi Y, Egan G, Meruelo D: Extension of the H-2 TLb molecular map. Isolation and characterization of TI3, TI4, and TI5 from the C57BL/6 mouse. Immunogenetics 1988, 27(4):239-25I.

25. Guidry PA, Stroynowski I: The murine family of gut-restricted class Ib MHC includes alternatively spliced isoforms of the proposed HLA-G homolog, "blastocyst MHC". J Immunol 2005, I 75(8):5248-5259.

26. Klein J, Benoist C, David CS, Demant P, Lindahl KF, Flaherty L, Flavell RA, Hammerling U, Hood LE, Hunt SW 3rd, et al.: Revised nomenclature of mouse $\mathbf{H - 2}$ genes. Immunogenetics 1990, 32(3): $147-149$.

27. Shiina T, Tamiya G, Oka A, Takishima N, Yamagata T, Kikkawa E, Iwata K, Tomizawa M, Okuaki N, Kuwano Y, Watanabe K, Fukuzum Y, Itakura S, Sugawara C, Ono A, Yamazaki M, Tashiro H, Ando A, lkemura T, Soeda E, Kimura M, Bahram S, Inoko H: Molecular dynamics of MHC genesis unraveled by sequence analysis of the I,796,938-bp HLA class I region. Proc Natl Acad Sci U S A 1999, 96(23): 13282-13287.

28. Kulski JK, Anzai T, Shiina T, Inoko H: Rhesus macaque class I duplicon structures, organization, and evolution within the alpha block of the major histocompatibility complex. Mol Biol Evol 2004, 2 I (I I):2079-209I.

29. Kulski JK, Gaudieri S, Martin A, Dawkins RL: Coevolution of PERB I I (MIC) and HLA class I genes with HERV-I 6 and retroelements by extended genomic duplication. J Mol Evol 1999 , 49(1):84-97.

30. Kumanovics A, Madan A, Qin S, Rowen L, Hood L, Fischer Lindahl K: QUOD ERAT FACIENDUM: sequence analysis of the H2-D 
and $\mathrm{H} 2-\mathrm{Q}$ regions of $\mathbf{1 2 9 / S v J}$ mice. Immunogenetics 2002, 54(7):479-489.

31. Oudshoorn-Snoek M, Demant P: Identification and expression of the Tla region gene TI Ib and its Qa-like product. J Immunol 1990, I45(4): 1270-1277.

32. Comiskey M, Goldstein CY, De Fazio SR, Mammolenti M, Newmark JA, Warner CM: Evidence that HLA-G is the functional homolog of mouse Qa-2, the Ped gene product. Hum Immunol 2003, 64(II):999-1004.

33. Wu L, Exley GE, Warner CM: Differential expression of Ped gene candidates in preimplantation mouse embryos. Biol Reprod 1998, 59(4):94I-952.

34. Tajima A, Tanaka T, Ebata T, Takeda K, Kawasaki A, Kelly JM, Darcy PK, Vance RE, Raulet DH, Kinoshita K, Okumura K, Smyth MJ, Yagita $\mathrm{H}$ : Blastocyst MHC, a putative murine homologue of HLA-G, protects TAP-deficient tumor cells from natural killer cellmediated rejection in vivo. J Immunol 2003, I7I(4): |7| 15-172I.

35. Lercher MJ, Blumenthal T, Hurst LD: Coexpression of neighboring genes in Caenorhabditis elegans is mostly due to operons and duplicate genes. Genome Res 2003, I3(2):238-243.

36. Aihara H, Hiwatashi N, Kumagai S, Obata Y, Shimosegawa T, Toyota $\mathrm{T}$, Miyazaki J: The T3(b) gene promoter directs intestinal epithelial cell-specific expression in transgenic mice. FEBS Lett 1999, 463(I-2): 185-188.

37. Kumar PP, Bischof O, Purbey PK, Notani D, Urlaub H, Dejean A, Galande S: Functional interaction between PML and SATBI regulates chromatin-loop architecture and transcription of the MHC class I locus. Nat Cell Biol 2007, 9(I):45-56.

38. Galande S, Purbey PK, Notani D, Kumar PP: The third dimension of gene regulation: organization of dynamic chromatin loopscape by SATB I. Curr Opin Genet Dev 2007, I7(5):408-4I4.

39. Teitell M, Cheroutre H, Panwala C, Holcombe H, Eghtesady P, Kronenberg $\mathrm{M}$ : Structure and function of $\mathrm{H}-2 \mathrm{~T}$ (Tla) region class I MHC molecules. Crit Rev Immunol I994, I 4(I): I-27.

40. Fischer Lindahl K: On naming $\mathbf{H} 2$ haplotypes: functional significance of MHC class Ib alleles. Immunogenetics 1997, 46(I):53-62.

41. Hurt P, Walter L, Sudbrak R, Klages S, Muller I, Shiina T, Inoko H, Lehrach $\mathrm{H}$, Gunther E, Reinhardt R, Himmelbauer $\mathrm{H}$ : The genomic sequence and comparative analysis of the rat major histocompatibility complex. Genome Res 2004, I4(4):63I-639.

42. NCBI Entrez Genome Project [http://www.ncbi.nlm.nih.gov/ sites/entrez]

43. Ensembl Mouse Genome Project [http://analysis I.lab.nig.ac.jp/ Mus musculus/index.html]

44. Burge C, Karlin S: Prediction of complete gene structures in human genomic DNA. J Mol Biol 1997, 268(I):78-94.

45. DNA Data Bank of Japan (DDBJ) CLUSTALW Analysis [http://clustalw.ddbj.nig.ac.jp/top-j.html]

46. Schwartz S, Zhang Z, Frazer KA, Smit A, Riemer C, Bouck J, Gibbs R, Hardison R, Miller W: PipMaker--a web server for aligning two genomic DNA sequences. Genome Res 2000, I0(4):577-586.

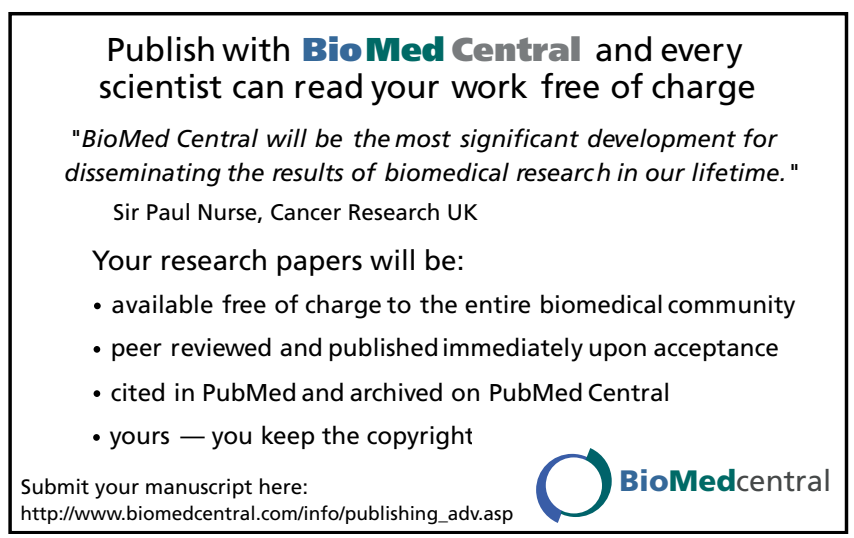

